\title{
Uso do resíduo de laranja lima e da casca de coco verde na produção de enzimas
}

\author{
Orange residue and green coconut shell employed on enzyme production \\ A. K. S. Abud ${ }^{1,2 *}$; M. L. Araújo ${ }^{2} ;$ R. M. R. G. Almeida ${ }^{2}$ \\ ${ }^{I}$ Departamento de Tecnologia de Alimentos/Universidade Federal de Sergipe, CEP 49100-000, São Cristóvão-SE, \\ Brasil \\ ${ }^{2}$ Programa de Pós-Graduação em Engenharia Química/Laboratório de Ensino em Engenharia Química, \\ Universidade Federal de Alagoas, CEP 57072-970, Maceió-AL, Brasil
}

*ana.abud@gmail.com

(Recebido em 22 de julho de 2015; aceito em 11 de setembro de 2015)

\begin{abstract}
Com uma economia baseada na produção agrícola, o Nordeste brasileiro apresenta grandes volumes de resíduos que, quando não adequadamente dispostos, geram problemas ambientais e de saúde, devido à atração de insetos e roedores e o mau cheiro oriundos do processo de degradação. Como alternativa para minorar tais problemas e agregar valor aos resíduos, com a formação de produtos de interesse comercial, surgem os processos biotecnológicos. A aplicação da fermentação semi-sólida (FSS) é uma destas alternativas, destacando-se por ser um processo simples e de baixo custo. Avaliou-se neste trabalho o uso de resíduos agroindustriais como substrato para a produção de enzimas hidrolíticas por fermentação semisólida a partir do fungo Aspergillus niger, conduzidas em frascos Erlenmeyers de $250 \mathrm{~mL}$ suplementados com meio mineral, de forma a se ter um conteúdo final de umidade em torno de $60 \%$. A cinética de crescimento foi acompanhada através de medida das atividades enzimáticas, acidez, $\mathrm{pH}$, açúcares redutores (AR) e açúcares redutores totais (ART). Os resultados obtidos mostraram boa eficiência na produção de poligalacturonase ao utilizar resíduos de casca de coco verde, bagaço de laranja lima e a mistura dos dois resíduos como substrato, sendo a maior atividade poligalacturonásica 52,48 U/g, 22, 52 $\mathrm{U} / \mathrm{g}$ e $38,68 \mathrm{U} / \mathrm{g}$, respectivamente, com fraca atividade de pectinase em ambos. Obtiveram-se baixos valores para as atividades de avicelase e carboximetilcelulase para todos os resíduos, o que indica a necessidade de um pré-tratamento alcalino para promover maior indução enzimática.

Palavras-chave: resíduos, fermentação semi-sólida, enzimas
\end{abstract}

With an economy based on agricultural production, the Brazilian Northeast has large volumes of waste, that, when not properly disposed, cause environmental and health problems due to the attraction of insects and rodents and the stink coming from the degradation process. As an alternative to mitigate these problems and add value to waste, with the formation of commercial interest products, biotechnological processes appear. The application of solid state fermentation (FSS) is one of these alternatives, especially for being a simple and inexpensive process. It was evaluated in this paper the use of agro-industrial wastes as substrate for hydrolytic enzymes production by solid state fermentation from the fungus Aspergillus niger, conducted in $250 \mathrm{~mL}$ Erlenmeyer flasks supplemented with mineral medium in a way to have a final moisture content around $60 \%$. The growth kinetics were monitored by measuring enzymatic activity, acidity, $\mathrm{pH}$, reducing sugars (RS) and total reducing sugars (TRS). The results showed good efficiency in the production of polygalacturonase using the waste green coconut, lime orange peel and mixing of the two wastes as substrate, the highest polygalacturonase activity was $52.48 \mathrm{U} / \mathrm{g}, 2252$ $\mathrm{U} / \mathrm{g}$ and $38.68 \mathrm{U} / \mathrm{g}$, respectively, with weak activity in both pectinase. Lower values were also obtained for avicelase and carboxymethylcellulase activities for all wastes, indicating the need of an alkali pretreatment to promote greater enzyme induction.Insert the abstract here.

Keywords: waste, solid state fermentation, enzymes

\section{INTRODUÇÃO}

A indústria de alimentos produz uma série de resíduos, o que tem gerado uma preocupação com o meio ambiente. Com isso, inúmeros estudos têm sido realizados utilizando esses subprodutos, os quais têm mostrado o seu alto valor de reutilização. $\mathrm{O}$ aproveitamento de 
resíduos possibilita minimizar o impacto ambiental destes tipos de indústrias na região onde estão situadas e, ainda, agregar valor aos produtos do mercado [1].

O aumento na produção e consumo da água de coco colocou o Brasil na atual posição de líder mundial na produção de coco verde. A laranja também está entre as frutas mais produzidas e consumidas no mundo. Em Alagoas, a região de Santana do Mundaú é referência para o Nordeste na produção de laranja lima mas, em função da fácil suscetibilidade à degradação, são observados altos índices de desperdício da fruta durante a comercialização [2]. Com isto, tais culturas geram grandes quantidades de resíduos, que acarretam em um sério problema ambiental.

Como alternativa, vem sendo dada atenção ao reaproveitamento destes nos diferentes processos industriais como, por exemplo, em processos fermentativos, na produção de enzimas. As enzimas são catalisadores biológicos bastante atraentes para a aplicação industrial, principalmente pela sua ação eficiente e seletiva. As reações mediadas por biocatalisadores oferecem ainda como vantagens, elevados rendimentos com excelentes níveis de pureza, e minimização da formação de subprodutos, ocorrendo em condições reacionais brandas [3].

A utilização da fermentação semi-sólida tem apresentado algumas vantagens como simular o habitat natural do fungos filamentosos empregados, favorecendo o crescimento destes microrganismos, proporcionar uma maior produtividade de enzimas quando comparada ao processo de fermentação submersa e possibilitar a utilização de resíduos agroindustriais como substrato sólido, servindo estes como fontes de carbono e energia [4].

As enzimas, tais como poligalacturonase e pectinase, entre outras, são aplicadas na indústria de processamento de sucos sendo usadas nas etapas de extração, clarificação, concentração e também em processos fermentativos de café e chá, tratamento de resíduos vegetais e extração de óleos [5].

As celulases podem ser utilizadas em vários processos na indústria como na indústria têxtil, no mercado de detergentes, de papel, no tratamento de resíduos e na produção de bioetanol em usinas com destilaria em anexo [6]. São capazes de serem produzidas por diversas espécies de fungos, sendo os principais gêneros produtores Trichoderma, Penicillium, Aspergillus e Fusarium [7].

Devido à grande disponibilidade de resíduos de casca de coco verde e bagaço de laranja lima na região Nordeste e a possibilidade de agregar valor a tais resíduos, propõe-se, neste trabalho, o uso do pó da casca de coco verde e do bagaço de laranja lima como substrato na produção de enzimas pectinolíticas (pectinase e poligalacturonase) e celulolíticas (carboximetilcelulase e avicelase) pelo fungo Aspergillus niger através de fermentação semi-sólida.

\section{MATERIAL E MÉTODOS}

Os resíduos empregados foram o bagaço de laranja lima e a casca de coco verde. O coco verde foi obtido em quiosque da UFAL e a laranja lima foi cedida pela COOPLAL (Cooperativa dos Produtores de Laranja Lima de Santana do Mundaú, Alagoas).

Após a seleção dos cocos, o material foi dilacerado com facão. O bagaço de laranja lima, constituído de albedo, foi obtido após a extração do suco, sendo cortado em pequenos pedaços.

A casca de coco e o bagaço passaram por processos de lavagem e sanitização em hipoclorito de sódio a $100 \mathrm{ppm}$ por 15 min para, então, ser realizada a secagem a $50{ }^{\circ} \mathrm{C}$, até se obter peso constante, sendo moídos em moinho de facas tipo Willye, em peneira de $30 \mathrm{mesh}$, e acondicionados em embalagens plásticas herméticas.

O microrganismo utilizado nos experimentos de fermentação foi uma linhagem de Aspergillus niger isolada do solo, gentilmente cedida pelo BIOSE da Universidade Federal do Rio de Janeiro (UFRJ) e mantida em meio ágar batata dextrose a $4{ }^{\circ} \mathrm{C}$.

As fermentações foram conduzidas em frascos Erlenmeyer de $250 \mathrm{~mL}$, cobertos com tampão de algodão. $\mathrm{O}$ volume de solução mineral $\left[\left(\mathrm{NH}_{4}\right)_{2} \mathrm{SO}_{4}, 10 \mathrm{~g} / \mathrm{L} ; \mathrm{MnSO}_{4}, 0,005 \mathrm{~g} / \mathrm{L}\right.$; $\mathrm{MgSO}_{4} .7 \mathrm{H}_{2} \mathrm{O}, 1 \mathrm{~g} / \mathrm{L} ; \mathrm{FeSO}_{4} .7 \mathrm{H}_{2} \mathrm{O}, 0,005 \mathrm{~g} / \mathrm{L} ; \mathrm{KH}_{2} \mathrm{PO}_{4}, 3 \mathrm{~g} / \mathrm{L} ; \mathrm{ZnSO}_{4}, 0,005 \mathrm{~g} / \mathrm{L}$ e $\mathrm{CaCl}_{2}, 0,5$ $\mathrm{g} / \mathrm{L}]$ adicionado a cada frasco foi previamente definido, de forma a se ter um conteúdo final de 
umidade em torno de $60 \%$. Os frascos foram inoculados com uma suspensão de $2,9.10^{7}$ esporos por grama de resíduo, preparada em Tween- $800,1 \% \mathrm{v} / \mathrm{v}$.

Após a inoculação, os frascos Erlenmeyer foram encaminhados à estufa bacteriológica a 30 ${ }^{\circ} \mathrm{C}$. Ao longo do tempo, retiraram-se amostras para avaliar a cinética fermentativa a partir do extrato, de onde eram medidos o teor de açúcares, o pH, a acidez e a atividade enzimática. Para extração, adicionou-se $50 \mathrm{~mL}$ de solução e agitou por $30 \mathrm{~min}$ em shaker a $100 \mathrm{rpm}$. A amostra foi filtrada em algodão, centrifugada a $3000 \mathrm{rpm}$ por $10 \mathrm{~min}$, filtrada em papel de filtro qualitativo e armazenada em freezer até o instante da análise.

Para a determinação de açúcares redutores (AR) e redutores totais (ART) foi utilizado o método colorimétrico do ácido 3,5-dinitrosalicílico (DNS), descrito segundo Miller (1959) [8]. Para a determinação de ART foi realizado tratamento em $\mathrm{H}_{2} \mathrm{SO}_{4} 1,5 \mathrm{M}$, em banho fervente por 30 min, com agitação ocasional para hidrolisar os polissacarídeos e outros açúcares não redutores.

$\mathrm{O} \mathrm{pH}$ foi determinado eletronicamente, por meio de potenciômetro e eletrodo, previamente ajustado em soluções tampão pH 4,0 e 7,0. A medida de acidez foi baseada na titulação de neutralização de ácidos com solução padronizada de álcali (solução de $\mathrm{NaOH} 0,1 \mathrm{~N}$ ) e com o uso de indicador fenolftaleína, segundo a metodologia Instituto Adolfo Lutz (IAL, 2005) [9].

Para a determinação das atividades enzimáticas foi necessária a inativação de uma parte do extrato a fim de eliminar a atuação de açúcares e enzimas pré-existentes como interferentes. Para isto, uma parte da amostra foi colocada em ebulição por 5 min e resfriada em banho de gelo. Assim, as análises de atividade constaram de duas amostras, uma ativa e outra inativa, sendo a atividade determinada pela diferença entre as mesmas.

A atividade de pectinase foi realizada conforme procedimento descrito por Gieze et al. (2008) [10], que consistiu em adicionar $0,8 \mathrm{~mL}$ de extrato a $0,2 \mathrm{~mL}$ de tampão acetato de sódio $0,05 \mathrm{M} \mathrm{pH} \mathrm{5,0} \mathrm{contendo} 1 \%$ de pectina cítrica, incubando em banho-maria a $50^{\circ} \mathrm{C}$ por $15 \mathrm{~min}$. A atividade de poligalacturonase (exo-poligalacturonase) foi realizada conforme procedimento descrito por Martins et al. (2013) [11], colocando-se 0,2 mL de extrato em contato com 0,8 mL de tampão acetato de sódio $0,2 \mathrm{M} \mathrm{pH} \mathrm{5,0} \mathrm{contendo} 1 \%$ de pectina cítrica, incubando em banhomaria a $60^{\circ} \mathrm{C}$ por $10 \mathrm{~min}$. As medidas de atividade foram realizadas por DNS, tendo como padrão uma curva com concentrações conhecidas de ácido galacturônico. Uma unidade de atividade foi definida como sendo a quantidade de enzima que libera $1 \mu \mathrm{mol}$ de ácido galacturônico por minuto, nas condições de ensaio.

A atividade de avicelase (EC 3.2.1.91) foi realizada conforme metodologia descrita por Oliveira et al. (2014) [12], que consistiu na adição de $1 \mathrm{~mL}$ do extrato a $1 \mathrm{~mL}$ de solução $1 \%$ de celulose microcristalina (avicel), em tampão acetato $0,05 \mathrm{M} \mathrm{e} \mathrm{pH} \mathrm{5,0,} \mathrm{e} \mathrm{incubado} \mathrm{a} 50^{\circ} \mathrm{C}$, por 30 minutos. A atividade de carboximetilcelulase (CMCase, EC 3.2.1.4 ) consistiu na adição de 1 $\mathrm{mL}$ do extrato em $1 \mathrm{~mL}$ de solução de carboximetilcelulose $1 \%$ em tampão acetato $0,05 \mathrm{M}, \mathrm{pH}$ 5,0 e incubado a $50^{\circ} \mathrm{C}$, por 30 minutos. Periodicamente, o sistema substrato-enzima foi agitado com a finalidade de manter o substrato em suspensão. A determinação da atividade da amostra foi realizada por DNS, tendo como padrão uma curva com concentrações conhecidas de glicose. Uma unidade de atividade foi definida como sendo a quantidade de enzima que libera $1 \mu \mathrm{mol}$ de glicose por minuto, nas condições de ensaio.

\section{RESULTADOS E DISCUSSÃO}

As Figuras 1 e 2 ilustram as cinéticas de consumo de açúcares. Pode-se perceber um estágio de adaptação do fungo ao meio de fermentação nas primeiras 24 horas, quando então se inicia o consumo de açúcares e produção de ácido cítrico. A formação micelial foi observada em 48 horas, acarretando no consumo de açúcares redutores presentes no meio. Isso ocorre devido ao Aspergillus niger não ser capaz de hidrolisar a sacarose no início de seu crescimento, pois somente após a formação dos micélios é que juntamente com estes é formada a enzima invertase extracelular, capaz de hidrolisar sacarose em meio ácido. Assim, a maior produção de ácido cítrico se deu em 48 horas (48,50 g ác. cítrico/mL de resíduo) quando já havia sido formada 
biomassa suficiente e todo o açúcar necessário estava disponível ao metabolismo e produção do ácido cítrico.

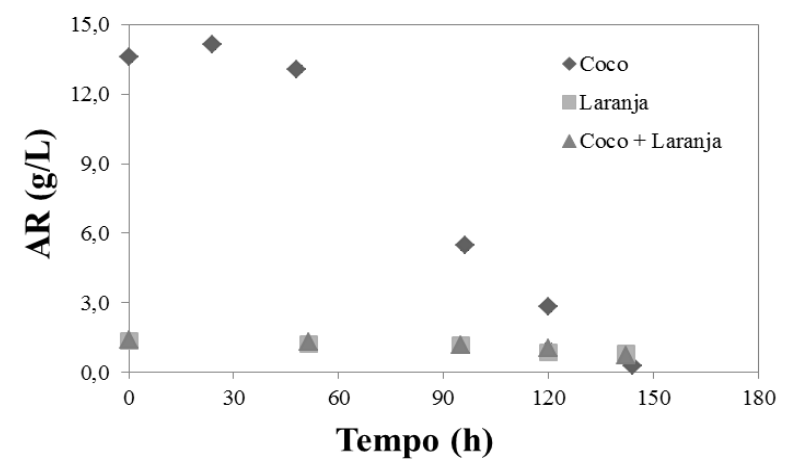

Figura 1. Cinética do consumo de glicose para os diferentes resíduos.

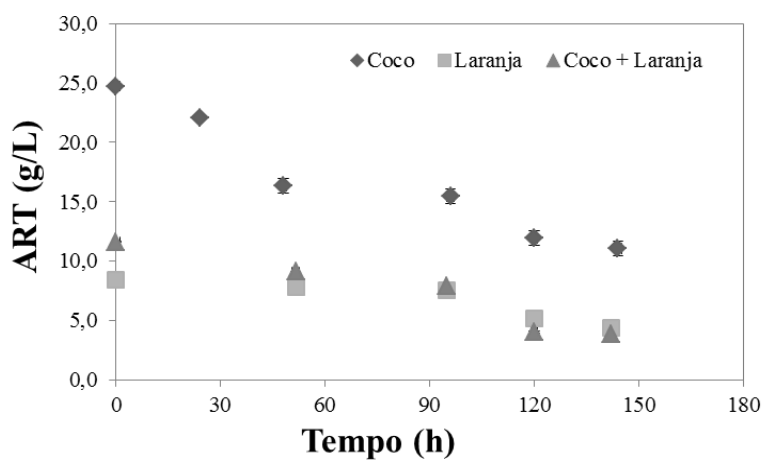

Figura 2. Cinética do consumo de ART para os diferentes resíduos.

Os resultados apresentados mostraram que a casca de coco teve um consumo de açúcares redutores totais (ART) de 55,4\% e consumo de $97,8 \%$ dos açúcares em forma de glicose. O bagaço de laranja teve um consumo de açúcares redutores totais (ART) de 47,8\% e consumo de $40,6 \%$ dos açúcares redutores. A mistura de casca de coco com o bagaço de laranja teve um consumo de açúcares redutores totais (ART) de 67,0\% e consumo de 46,6\% de glicose.

As Figuras 3 e 4 apresentam a acidez em ácido cítrico e o $\mathrm{pH}$ ao longo do processo fermentativo. Como pode ser observado, os valores do $\mathrm{pH}$ para a casca de coco diminuem. Esta redução no $\mathrm{pH}$ do meio de fermentação a partir do $2^{\circ}$ dia ocorreu devido ao início do acúmulo de ácido cítrico no meio de fermentação, sendo os menores valores de $\mathrm{pH}(2,17$ e 2,33) alcançados nos dias de maior produção de ácido cítrico, como o $3^{\circ}$ dia de fermentação, que gerou $6,32 \mathrm{~g}$ de ác. cítrico/g de resíduo.

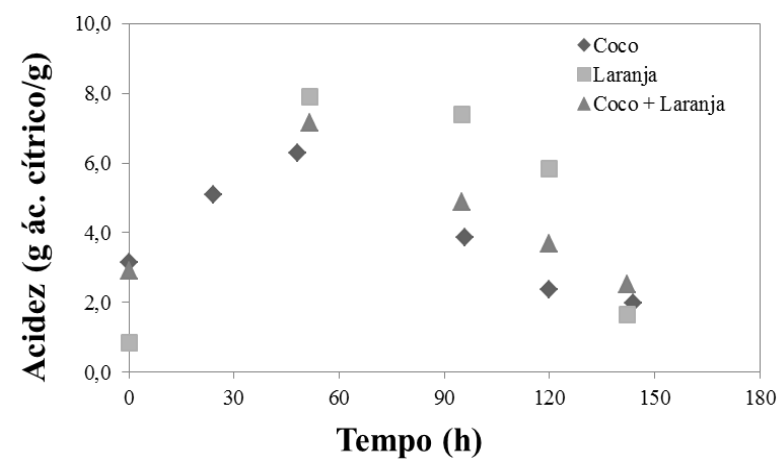

Figura 3. Acompanhamento da acidez para extratos dos diferentes resíduos. 


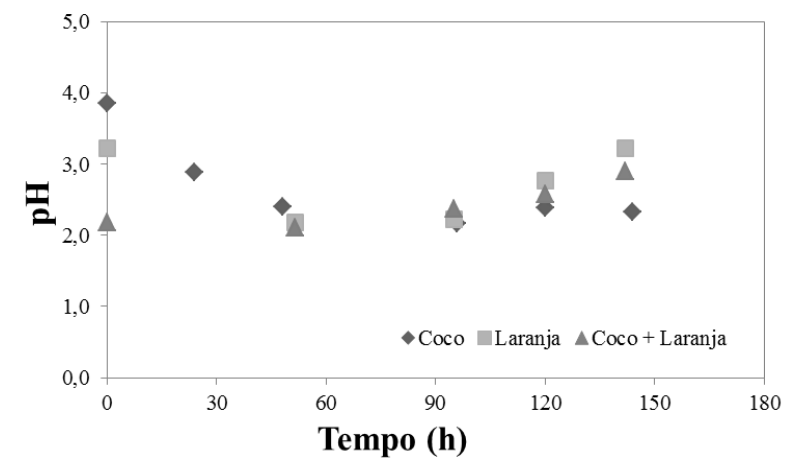

Figura 4. Valores de pH para os extratos fermentados nos diferentes resíduos.

Para o bagaço de laranja, a maior produção de ácido cítrico ocorreu no $2^{\circ}$ dia de fermentação (7,95 g de ác. cítrico/g de resíduo). A partir deste ponto, os valores de $\mathrm{pH}$ subiram um pouco devido ao abaixamento na quantidade de ácido presente no meio.

Para a produção de ácido cítrico, em relação à mistura de bagaço de laranja e casca de coco, percebeu-se que a adição do suporte causa diminuição da quantidade produzida, possivelmente devido ao fato da quantidade de bagaço de laranja ter sido diminuída de um ensaio para o outro, sendo substituída pela casca de coco, que possuiu uma via de degradação mais lenta em função da quantidade lignocelulósica de sua composição, diminuindo, consequentemente, a formação do ácido. Estes resultados podem ser observados na Figura 4, onde se percebeu uma maior produção de ácido cítrico em 51,5 horas de fermentação para o ensaio com bagaço de laranja lima.

As Figuras 5 a 8 apresentam as cinéticas de formação e degradação das enzimas pectinase, poligalacturonase, avicelase e carboximetilcelulase, respectivamente.

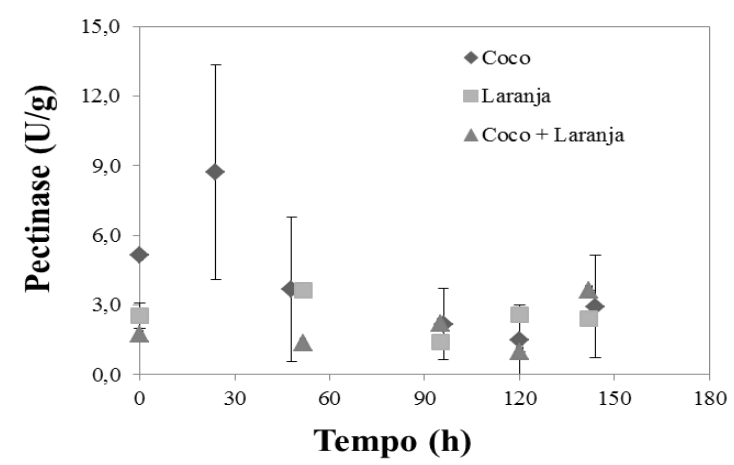

Figura 5. Cinética de ação da pectinase para os diferentes resíduos.

Observou-se a maior formação de poligalacturonase no processo com apenas casca de coco $(52,48 \mathrm{U} / \mathrm{g}$, equivalente a $7,92 \mathrm{U} / \mathrm{mL})$, bem como de pectinase $(8,75 \mathrm{U} / \mathrm{g}$, equivalente a 1,32 $\mathrm{U} / \mathrm{mL}$ ), ambas em 24 horas de fermentação. Contudo, nas duas determinações, o resultado de atividade apresentou, em seguida, uma tendência constante de decréscimo.

Percebeu-se, também, que no bagaço de laranja a maior atividade da poligalacturonase foi $22,52 \mathrm{U} / \mathrm{g}$ (equivalente a $3,36 \mathrm{U} / \mathrm{mL}$ ) e de pectinase foi de $3,63 \mathrm{U} / \mathrm{g}$ (equivalente a $0,54 \mathrm{U} / \mathrm{mL}$ ), ambas em 24 horas de fermentação.

Souza et al. (2010) [13] observaram a produção de poligalacturonase utilizando resíduo de maracujá como substrato a partir de $7 \mathrm{~h}$ de fermentação e um pico de atividade igual a $20,9 \mathrm{U} / \mathrm{g}$ em $66 \mathrm{~h}$ de processo. Santos et al. (2008a) [14] alcançaram, estudando a produção de poligalacturonase por fermentação semi-sólida e utilizando pedúnculo de caju como substrato, $10,1 \mathrm{U} / \mathrm{g}$ para uma umidade inicial de $40 \%$ e a concentração da fonte de nitrogênio igual a $1 \%$. Botella et al. (2007) [15] observaram o efeito da umidade inicial e a suplementação com uma 
fonte de carbono na produção de pectinase e xilanase por Aspergillus awamori, com polpa de uva como substrato. A máxima produção foi de aproximadamente $40 \mathrm{U} / \mathrm{mL}$ em $48 \mathrm{~h}$ de cultivo. Santos et al. (2008b) [16] destacam que a umidade inicial do meio é a variável mais importante para o processo de produção de pectinases.

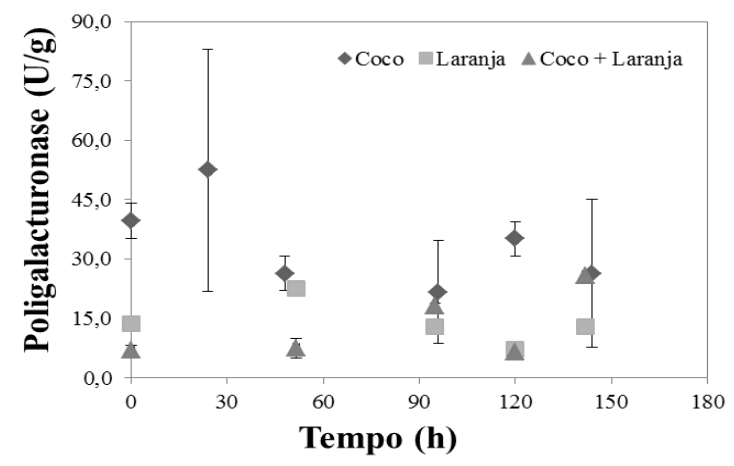

Figura 6. Atividade de poligalacturonase para os diferentes resíduos.

As maiores atividades de poligalacturonase $(38,68 \mathrm{U} / \mathrm{g}$, equivalente a $3,87 \mathrm{U} / \mathrm{mL})$ e de pectinase $(5,42 \mathrm{U} / \mathrm{g}$, equivalente a $0,54 \mathrm{U} / \mathrm{mL})$ para os ensaios de bagaço de laranja + casca de coco ocorreram em 142 horas de fermentação, ressaltando a importância de se utilizar um suporte de imobilização como a casca de coco.

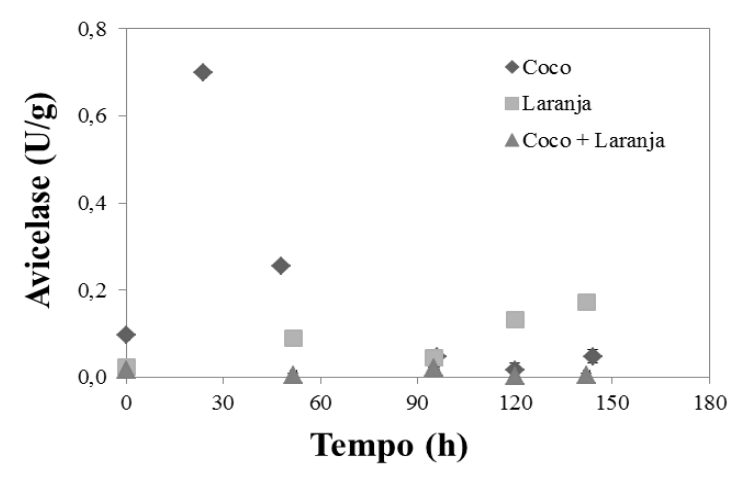

Figura 7. Atividade de avicelase para os diferentes resíduos.

A produção de avicelase e de carboximetilcelulase para a casca de coco foi maior no $2^{\circ}$ dia, gerando $0,70 \mathrm{U} / \mathrm{g}$ (equivalente a $0,21 \mathrm{U} / \mathrm{mL}$ ) e $0,41 \mathrm{U} / \mathrm{g}$ (equivalente a $0,12 \mathrm{U} / \mathrm{mL}$ ), respectivamente. Os baixos níveis de produção de celulase nos substratos analisados podem ter sua explicação no fato de os resíduos não terem sofrido qualquer tipo de pré-tratamento para reduzir sua recalcitrância, uma vez que a lignina confere uma limitação para a assimilação da fonte de carbono pelo micro-organismo agente da fermentação. Esta suposição é confirmada pelos dados da literatura, que referenciam maior produção de celulases em resíduos que sofreram pré-tratamento [17].

Silva et al. (2009) [18] mostram a necessidade do pré-tratamento para promover maior indução enzimática, ao testar seis fungos na presença de casca da acácia tratada e não tratada e observou que, quando não ocorreu o tratamento alcalino da casca, a atividade celulásica foi baixa. 


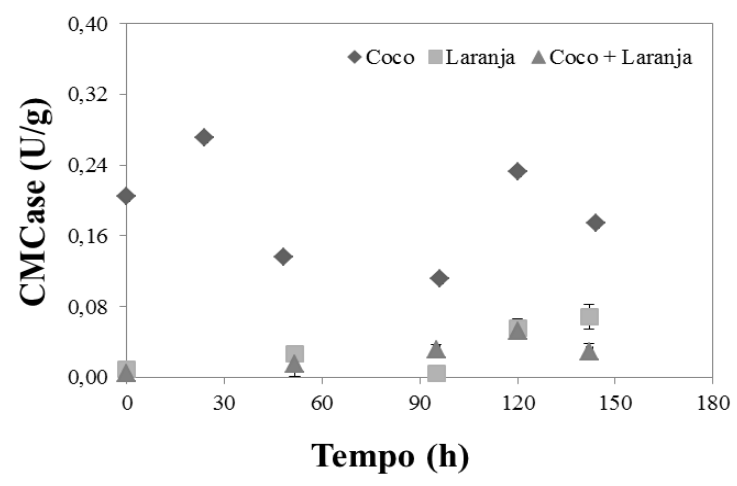

Figura 8. Atividade de carboximetilcelulase para os diferentes resíduos.

Para o bagaço de laranja, a maior produção foi observada em 142 horas $(0,07 \mathrm{U} / \mathrm{g}$ que equivale a $0,02 \mathrm{U} / \mathrm{mL}$ ). E, para a mistura de bagaço de laranja e casca de coco pode-se observar que a maior produção de carboximetilcelulase foi em 120 horas $(0,052 \mathrm{U} / \mathrm{g}$, que equivale a 0,02 $\mathrm{U} / \mathrm{mL})$ e a maior atividade de celulase foi em 95 horas $(0,021 \mathrm{U} / \mathrm{g}$, equivalente a $0,006 \mathrm{U} / \mathrm{mL})$.

Os resultados de Menezes et al. (2009) [19] também não demonstraram grandes valores ao utilizar bagaço de cana e fungos do gênero Pleurotus ( $P$. sp BCCB068, $P$. tailandia e P. sajorcaju). Tendo a maior atividade alcançada com a linhagem Pleurotus sajor-caju com 0,08 U/mL $\left(20^{\circ}\right.$ e $25^{\circ}$ dias de incubação). E apresentou a maior atividade de carboximetilcelulase produzida pela linhagem Pleurotus tailandia com $0,06 \mathrm{U} / \mathrm{mL}$ no $10^{\circ}$ dia de incubação.

Reddy et al. (2003) [20] estudaram a atividade enzimática celulolítica de fungos Pleurotus ostreatus e Pleurotus sajor-caju, utilizando substrato de resíduos lignocelulósicos de banana em fermentação semi-sólida, obtendo também baixa atividade celulolítica.

\section{CONCLUSÃO}

Os resultados mostram que a fermentação semi-sólida constitui-se numa alternativa de aproveitamento de resíduos agroindustriais tornando-os produtos de alto valor agregado como enzimas e ácidos orgânicos. A utilização da farinha da casca de coco verde como substrato mostrou maior capacidade da produção de enzimas, em relação à farinha do bagaço de laranja lima e à mistura dos dois resíduos. Obtiveram-se baixas atividades para enzimas lignolíticas, possivelmente em função do baixo $\mathrm{pH}$ no meio e de condições de recalcitrância, limitando o desenvolvimento microbiano.

\section{AGRADECIMENTOS}

Os autores agradecem ao CNPq pelo auxílio financeiro e à CAPES pela bolsa concedida.

\section{REFERÊNCIAS BIBLIOGRÁFICAS}

1. Pelizer LH, Pontieri MH, Moraes IO. Utilização de resíduos agro-industriais em processos biotecnológicos como perspectiva de redução do impacto ambiental. Journal of Technology Management \& Innovation. 2007; 2:118-127.

2. Ferreira JTP, Ferreira EP, Pantaleão FS, Albuquerque KN, Ferreira AC. Citricultura em Santana do Mundaú, Alagoas, Brasil: histórico, evolução e oportunidades. Citrus Research \& Technology. 2013; 34: 1-8.

3. Baptista NMQ, Santos AC, Arruda FVF, Gusmão NB. Produção das enzimas lignina peroxidase e lacase por fungos filamentosos. Scientia Plena. 2012; 8(1):1-7.

4. Farinas CS, Lemo V, Rodríguez-Zúñiga UF, Neto VB, Couri S. Avaliação de diferentes resíduos agroindustriais como substratos para a produção de celulases por fermentação semi-sólida. Empresa 
Brasileira de Pesquisa Agropecuária: Embrapa Instrumentação Agropecuária. São Carlos, SP; 2008. $13 \mathrm{p}$.

5. Uenojo M, Pastore GM. Isolamento e seleção de microrganismos pectinolíticos a partir de resíduos provenientes de agroindústrias. Ciência e Tecnologia de Alimentos. 2006 Jul-Set; 26(3): 509-515.

6. Aguiar CM, Lucena SL. Produção de celulases por Aspergillus niger e cinética da desativação celulásica. Acta Scientiarum Technology. 2011; 33(4): 385-391.

7. Dashtban M, Schraft H, Qin W. Fungal bioconversion of lignocellulosic residues: opportunities and perspectives. International Journal of Biological Sciences. 2009; 5(6): 578-595.

8. Miller GL. Use of dinitrosalicilic acid reagent for determination of reducing sugar. Analytical Chemistry. 1959; 31(3):426-428.

9. Instituto Adolfo Lutz. Normas Analíticas do Instituto Adolfo Lutz: Métodos Químicos para Análise de Alimentos. 4 ed. São Paulo: Instituto Adolfo Lutz (IAL); 2008. 533 p.

10. Giese EC, Dekker RFH, Barbosa AM. Orange bagasse as substrate for the production of pectinase and laccase by Botryosphaeria rhodina MAMB-05 in submerged and solid state fermentation. BioResources. 2008; 3(2): 335-345.

11. Martins ES, Leite RSR, Silva R, Gomes E. Purification and properties of polygalacturonase produced Thermoascus aurantiacus CBMAI-756 on solid state fermentation. Enzyme Research. 2013; 1-7.

12. Oliveira LRC, Barbosa JB, Martins MLL, Martins MA. Extracellular production of avicelase by the thermophilic soil bacterium Bacillus sp. SMIA-2. Acta Scientiarum Technology. 2014; 36(2): 215 222.

13. Souza RLA, Oliveira LSC, Silva FLH, Amorim BC. Caracterização da poligalacturonase produzida por fermentação semi-sólida utilizando-se resíduo do maracujá como substrato. Revista Brasileira de Engenharia Agrícola e Ambiental. 2010; 14(9):987-992.

14. Santos FM, Macedo GR, Silva FLH, Souza RLA, Pinto GA. Aplicação da metodologia de superfície de resposta no estudo da produção e extração da poligalacturonase. Química Nova. 2008; 31(8):19731978.

15. Botella C, Diaz A, Ory I, Webb C, Blandino A. Xilanase and pectinase production by Aspergillus awamori on grape pomace in solid state fermentation. Process Biochemistry. 2007; 43(1): 98-101.

16. Santos SFM, Souza RLA, Alcântara SR, Pinto GAS, Silva FLH, Macedo GR. Aplicação da metodologia de superfície de resposta no estudo da produção de pectinase por fermentação em estado sólido do pedúnculo de caju. Revista Brasileira de Produtos Agroindustriais. 2008; 10(2):101-109.

17. Oliveira SLR, Maciel TC, Pereira ALF, Rodrigues R. Produção de celulase por Aspergillus heteromophus URM 269 utilizando a casca do coco verde (Cocos nucifera L.) como substrato. Anais do IX Encontro de Pesquisa e Pós-Graduação do IFCE; 2009 Dez 09-12; Fortaleza, CE.

18. Silva LAD, Lopes FC, Silveira ST, Brandelli A. Production of cellulotic enzymes by Aspergillus phoenicis in grape waste using response surface methodology. Applied Biochemistry and Biotechnology. 2009; 152: 295-305.

19. Menezes CR, Silva IS, Durrant LR. Bagaço de cana: fonte para produção de enzimas ligninocelulolíticas. Estudos Tecnológicos. 2009; 5(1):68-78.

20. Reddy GV, Babu R, Komaraiah P, Roy KRRM, Kothari IL. Utilization of banana waste for the production of lignolytic and cellulolytic enzymes by solid substrate fermentation using two Pleurotus species (P.ostreatus and P. sajor-caju). Process Biochemistry. 2003; 38:1457-1462. 